\title{
Effective Second-Line Treatment with Cetuximab and Bevacizumab in a Patient with Hepatic Metastases of Colorectal Cancer and Hyperbilirubinemia
}

\author{
Nicolas Moosmann ${ }^{\mathrm{a}} \quad$ Dorit Laessiga ${ }^{\mathrm{a}}$ Henrik Jakob Michaely ${ }^{\mathrm{b}}$ Christoph Schulz ${ }^{\mathrm{a}}$ \\ Volker Heinemann ${ }^{a}$ \\ ${ }^{a}$ Medizinische Klinik III, \\ ${ }^{\mathrm{b}}$ Institut für Radiologie, Campus Großhadern, Klinikum der Ludwig-Maximilians-Universität München, Germany
}

Key Words

Hepatic metastases · Hyperbilirubinemia · Cetuximab · Bevacizumab

\section{Summary}

Background: Irinotecan-based second-line chemotherapy of metastatic colorectal cancer (CRC) is effective, it might, however, be contraindicated in cases of severe liver dysfunction due to advanced liver metastases. Case Report: A 57-year-old woman with diffuse CRC liver metastases showed progressive disease on first-line treatment with capecitabine and oxaliplatin (XELOX). Chronic cholestasis and hyperbilirubinemia caused by advanced liver involvement prohibited second-line treatment with irinotecan-based chemotherapy. We initiated combined antibody treatment with cetuximab and bevacizumab. Results: Clinical performance status as well as laboratory parameters improved rapidly. Staging investigations after 8 weeks revealed a partial remission. Since bilirubin levels had returned to the upper limit of normal, therapy could be changed to standard irinotecan, 5-fluorouracil, folinic acid, and bevacizumab. Conclusion: Combined treatment with cetuximab and bevacizumab may be considered as an effective treatment option in patients who cannot be treated with standard chemotherapy regimens due to impaired liver metabolism of cytotoxic substances.
Schlüsselwörter

Lebermetastasen · Hyperbilirubinämie · Cetuximab . Bevacizumab

\section{Zusammenfassung}

Hintergrund: Eine Irinotecan-basierte ZweitlinienChemotherapie bei metastasiertem kolorektalem Karzinom ist wirksam, kann jedoch bei ausgeprägter Leberfunktionseinschränkung aufgrund fortgeschrittener hepatischer Metastasierung kontraindiziert sein. Fallbericht: Eine 57-jährige Patientin mit diffuser Lebermetastasierung eines kolorektalen Karzinomes entwickelte unter der Erstlinientherapie mit Capecitabin und Oxaliplatin (XELOX) einen Krankheitsprogress. Aufgrund der ausgeprägten Lebermetastasierung, einhergehend mit chronischer Cholestase und Hyperbilirubinämie, war eine Zweitlinientherapie mit Irinotecan jedoch kontraindiziert. In dieser Situation leiteten wir eine kombinierte Behandlung mit Cetuximab und Bevacizumab ein. Ergebnisse: Sowohl der Allgemeinzustand der Patientin als auch die laborchemischen Parameter verbesserten sich unter Therapie rasch. Staging-Untersuchungen nach 8 Wochen ergaben den Befund einer partiellen Remission. Da die Bilirubinwerte zu diesem Zeitpunkt stabil im Bereich der oberen Normgrenze lagen, konnte die Behandlung auf eine Standardtherapie mit Irinotecan, 5-Fluorouracil, Folinsäure und Bevacizumab umgestellt werden. Schlussfolgerung: Eine kombinierte Antikörpertherapie bestehend aus Cetuximab und Bevacizumab kann als wirksame Therapieoption in Erwägung gezogen werden, wenn eine Standardchemotherapie aufgrund eingeschränkter Leberfunktion nicht appliziert werden darf.

\begin{tabular}{ll}
\hline KARGER & @ 2007 S. Karger GmbH, Freiburg \\
Fax +497614520714 & Accessible online at: \\
$\begin{array}{l}\text { E-mail Information@Karger.de } \\
\text { www.karger.com }\end{array}$ & www.karger.com/onk \\
&
\end{tabular}




\section{Introduction}

Colorectal cancer (CRC) is among the leading causes of death from cancer. It is estimated that approximately $50 \%$ of CRC patients develop metastases and eventually die of the disease [1]. Modern chemotherapy regimens for metastatic CRC combine 5-fluorouracil (5-FU) and folinic acid (FA) with irinotecan $\left(\right.$ Campto $^{\circledR}$, Pfizer Pharma GmbH, Karlsruhe, Germany) or oxaliplatin (Eloxatin $^{\circledR}, \quad$ Sanofi-Aventis Deutschland GmbH, Berlin, Germany). Infusional 5-FU, FA plus irinotecan (FOLFIRI) as well as infusional 5-FU, FA plus oxaliplatin (FOLFOX) achieve response rates of $49-62 \%$ and overall survival times of 16-20 months [2-4]. The vascular endothelial growth factor (VEGF) antibody bevacizumab (Avastin ${ }^{\circledR}$, Roche Pharma AG, Grenzach-Wyhlen, Germany) as well as the epidermal growth factor receptor (EGFR) antibody cetuximab (Erbitux ${ }^{\circledR}$, Merck Pharma GmbH, Darmstadt, Germany) can further improve chemotherapy efficacy and have been approved in this setting recently [5, 6]. Median survival times of the order of 20 months or above can, however, only be achieved if patients are able to receive all three cytotoxic drugs in the course of their disease [7]. This implies the presence of adequate liver and bone marrow parameters during first- and further-line treatment.

In CRC the liver is the most common organ of distant metastases. Therefore, liver dysfunction as well as chronic cholestasis with reduced hepatic and biliary excretion of various drug metabolites occur frequently in patients with marked hepatic involvement. The primary objective of this case report is to present an example of effective antineoplastic treatment despite severe liver dysfunction and hyperbilirubinemia

\section{Case Report}

We will discuss the case of a 57-year-old female patient who was diagnosed with adenocarcinoma of the sigmoid colon in February 2006. She presented with synchronous diffuse hepatic metastases at the time of initial diagnosis. After laparoscopic resection of the sigmoid, palliative chemotherapy with capecitabine (Xeloda ${ }^{\circledR}$, Roche Pharma AG) and oxaliplatin was started (XELOX). Staging investigations after 3 months of chemotherapy revealed progressive disease.

The patient first presented to our oncology department in August 2006 with distinct jaundice, right upper abdominal pain, ascites, and peripheral edema. Laboratory tests revealed marked elevation of liver parameters (bilirubin: $12.8 \mathrm{mg} / \mathrm{dl}$; alkaline phosphatase: 1,431 U/l; gamma-glutamyl transferase, gamma-GT: $612 \mathrm{U} / \mathrm{l}$; glutamic-pyruvic transaminase, GPT: 59 U/l; glutamic-oxalacetic transaminase, GOT: $380 \mathrm{U} / 1$ ), lactate dehydrogenase of $1,741 \mathrm{U} / \mathrm{l}$, and C-reactive protein of $19.9 \mathrm{mg} / \mathrm{dl}$. Abdominal ultrasound as well as contrast-enhanced CT scans of the thorax and abdomen showed diffuse hepatic metastases (liver involvement approximately $50 \%$ ), massive ascites, lymph node enlargement up to $4 \mathrm{~cm}$ close to the portal vein, and the beginnings of bilateral pleural effusion. There were no signs of biliary tract obstruction with dilatation that could have been treated by endoscopic or transhepatic biliary drainage. After the puncture of 3,000 $\mathrm{ml}$ ascites and initiation of antibiotic treatment, the general condition of our patient improved rapidly within a few days.

We then started a combined antibody treatment with cetuximab and bevacizumab. The patient received cetuximab $400 \mathrm{mg} / \mathrm{m}^{2}$ (loading dose, week 1) followed by $250 \mathrm{mg} / \mathrm{m}^{2}$ weekly combined with bevacizumab 5 $\mathrm{mg} / \mathrm{kg}$ every other week. Two weeks after initiation of treatment, her clinical performance status had improved dramatically, and treatment could be continued on an outpatient basis. Bilirubin levels decreased to $4.4 \mathrm{mg} / \mathrm{dl}, 3.2 \mathrm{mg} / \mathrm{dl}, 1.7 \mathrm{mg} / \mathrm{dl}$, and $1.0 \mathrm{mg} / \mathrm{dl}$ after $1,2,4$, and 8 weeks, respectively. Staging investigations including CT scans after 8 weeks of treatment revealed a partial remission of hepatic metastases as well as lymph node involvement. Only residual ascites was documented around the gallbladder (fig. 1). The tumor marker carcinoembryonic antigen (CEA) underlines the excellent response to the combined antibody treatment, decreasing from $2,311 \mathrm{ng} / \mathrm{ml}$ before the start of treatment to $302 \mathrm{ng} / \mathrm{ml}$ and $69 \mathrm{ng} / \mathrm{ml}$ after 4 and 8 weeks. Since bilirubin levels had remained stable $<1.5 \mathrm{mg} / \mathrm{dl}$ over a period of 3 weeks by that time, we could change treatment to FOLFIRI (irinotecan $180 \mathrm{mg} / \mathrm{m}^{2}$ as 90 -minute i.v. infusion, FA $400 \mathrm{mg} / \mathrm{m}^{2}$ as 2-hour i.v. infusion, 5-FU $400 \mathrm{mg} / \mathrm{m}^{2}$ as i.v. bolus, 5-FU 2,400 $\mathrm{mg} / \mathrm{m}^{2}$ as 46 -hour continuous i.v. infusion) plus beva-
Fig. 1. Computed tomography scans (coronal and transversal images) of a patient with advanced metastatic colorectal cancer. August 2006: Progressive disease after first-line treatment with XELOX; liver involvement approximately $50 \%$, ascites, and periportal lymph node metastases; October 2006: staging investigations after 8 weeks of combined treatment with cetuximab plus bevacizumab showing a partial remission; January 2007: staging investigations after 12 weeks of further treatment with FOLFIRI plus bevacizumab showing stable disease.

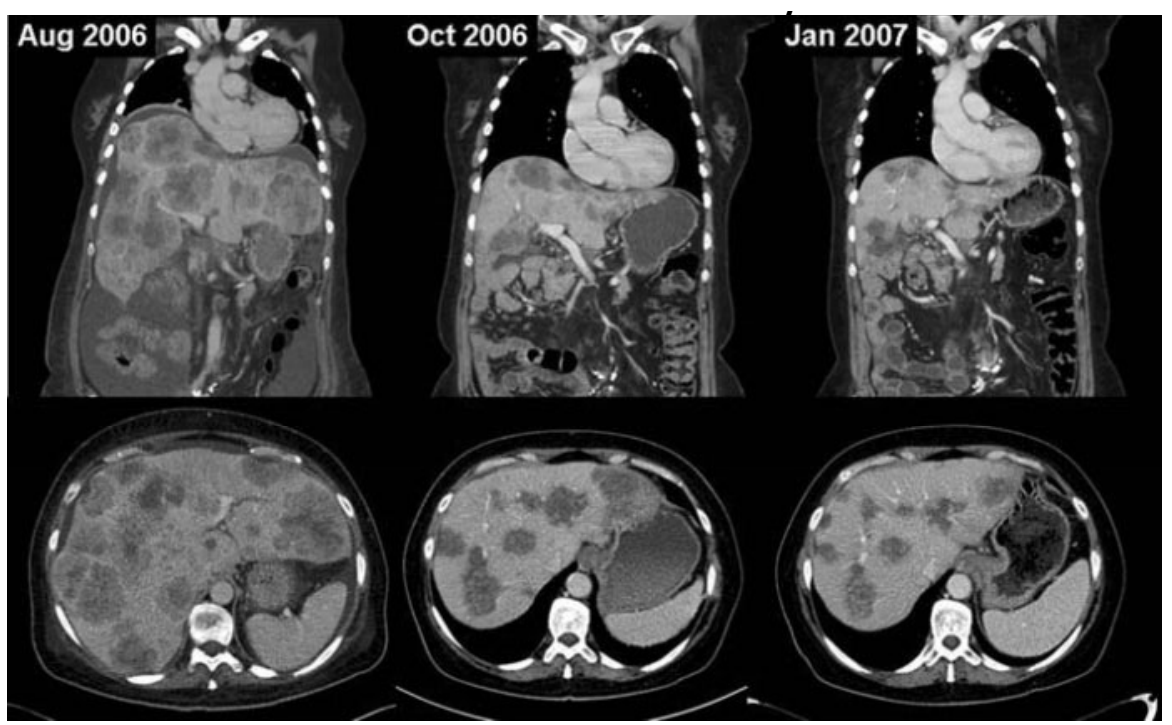


cizumab. We continued treatment on a biweekly schedule. Staging investigations after 5 cycles of FOLFIRI plus bevacizumab showed stable disease (fig. 1).

Altogether, our patient tolerated initial treatment with cetuximab plus bevacizumab very well. She was able to resume work after only 3 weeks of treatment. She suffered a maximum of grade 3 skin toxicity (symptomatic papulopustular rash affecting more than $50 \%$ of body surface) 3 weeks after the start of therapy. The rash improved rapidly to grade 1 skin toxicity by tetracyclines administered orally in combination with topical antiacne agents. She experienced no other clinically significant side effects. Tolerance of FOLFIRI plus bevacizumab, however, was slightly worse with grade 1 alopecia as well as grade 1 fatigue. Our patient is currently still on treatment with FOLFIRI plus bevacizumab.

\section{Discussion}

Second-line treatment with irinotecan-based chemotherapy after failure of first-line oxaliplatin-based treatment (or vice versa) is the current standard of care for patients suffering from metastatic CRC. Even though response rates are very modest in second-line setting, disease stabilization can again be achieved in $34-63 \%$ of patients [8].

However, the metabolism of irinotecan is dependent on liver function, particularly on bilirubin levels. Irinotecan is converted into its active metabolite $\mathrm{SN}-38$ by carboxylesterase enzymes. SN-38 is further metabolized and inactivated through conjugation into $\mathrm{SN}-38$ glucuronide $(\mathrm{SN}-38-\mathrm{G})$ by uridine diphosphate glucuronosyltransferase (UGT-1A1), the same isoenzyme responsible for glucuronidation of bilirubin. Thus, hyperbilirubinemia reflects deficiency of UGT-1A1 and leads to significantly reduced clearance of irinotecan and $\mathrm{SN}-38$. Irinotecan clearance is decreased by approximately $40 \%$ with bilirubin levels between 1.5 and $3 \times$ the upper limit of normal (ULN), and dose reduction is recommended. Once bilirubin levels exceed $3 \times$ ULN, application of irinotecan is contraindicated $[9,10]$.

The EGFR antibody cetuximab achieves response rates of approximately $11 \%$ in second- and further-line treatment. However, in Europe it is only approved when combined with irinotecan chemotherapy [5, 11]. Furthermore, there is no clinical evidence of bevacizumab activity when applied as a single substance [12]. Thus, there were no standard of care treatment options for our patient, who presented to our department after the failure of oxaliplatin- and fluoropyrimidine-based first-line treatment (XELOX) with severe liver dysfunction causing marked hyperbilirubinemia $>10 \mathrm{mg} / \mathrm{dl}$ due to hepatic metastases and chronic cholestasis.

We decided to initiate combined antibody treatment with bevacizumab and cetuximab. The chimeric IgG antibody cetuximab and the humanized IgG antibody bevacizumab follow a nonspecific elimination pathway, which is common for all antibodies. They are recognized by cells of the reticuloendothelial system that display receptors with binding affinity to the constant region of the antibody ( $\mathrm{Fc}$ fragment). Antibodies are degraded by internalization and further intracellular catabolism. Due to the very large number of receptors in the body, this elimination process is nonsaturable at therapeutic antibody levels, and it is not dependent on liver function [13]. Therefore cetuximab and bevacizumab could be safely applied at normal doses in our patient.

This combination was evaluated in a trial presented by Saltz et al. at ASCO 2005 [14]. The phase II study randomized 81 patients with irinotecan-refractory metastatic CRC to either cetuximab plus bevacizumab or cetuximab plus bevacizumab plus irinotecan. Nearly $90 \%$ of patients had additionally received prior oxaliplatin-based treatment. Even though patient numbers were limited, response rates of this heavily pretreated patient population were promising. The purely biological treatment (cetuximab plus bevacizumab) achieved a response rate of $23 \%$ and a disease control rate (partial remission + stable disease) of $77 \%$. The combination of cetuximab, bevacizumab, and irinotecan was even more effective $(35 \%$ partial response, $43 \%$ stable disease). Thus, the combination of the EGFR antibody plus the VEGF antibody was the most favorable treatment option we could propose to our patient. Fortunately treatment efficacy was impressive, with a rapid improvement of the clinical performance status and the abnormal liver function tests.

Since there is increasing evidence that skin rash can serve as a surrogate marker for response to cetuximab treatment, the fact that our patient developed grade 3 skin toxicity might reflect a particularly high sensitivity of her CRC tumor cells to the anti-EGFR treatment strategy $[5,15]$. After achieving a partial remission (fig. 1) as well as stable bilirubin levels, 'standard' second-line treatment with FOLFIRI plus bevacizumab was no longer contraindicated.

\section{Conclusion}

We propose that combined treatment with cetuximab and bevacizumab may be considered as an effective treatment option in patients who cannot be treated with standard chemotherapy regimens due to impaired metabolism of cytotoxic substances. 


\section{References}

1 Jemal A, Siegel R, Ward E, Murray T, Xu J, Smigal C, Thun MJ: Cancer statistics, 2006. CA Cancer J Clin 2006:56(2):106-30.

2 Douillard JY, Cunningham D, Roth AD, Navarro M, James RD, Karasek P, Jandik P, Iveson T, Carmichael J, Alakl M, Gruia G, Awad L, Rougier $P$ : Irinotecan combined with fluorouracil compared with fluorouracil alone as first-line treatment for metastatic colorectal cancer: a multicentre randomised trial. Lancet 2000;355(9209):1041-7.

3 Kohne CH, van Cutsem E, Wils J, Bokemeyer C, El-Serafi M, Lutz MP, Lorenz M, Reichardt P, Ruckle-Lanz H, Frickhofen N, Fuchs R, Mergenthaler HG, Langenbuch T, Vanhoefer U, Rougier P, Voigtmann R, Muller L, Genicot B, Anak O, Nordlinger B: Phase III study of weekly high-dose infusional fluorouracil plus folinic acid with or without irinotecan in patients with metastatic colorectal cancer: European Organisation for $\mathrm{Re}$ search and Treatment of Cancer Gastrointestinal Group Study 40986. J Clin Oncol 2005;23(22): 4856-65.

4 de Gramont A, Figer A, Seymour M, Homerin M, Hmissi A, Cassidy J, Boni C, Cortes-Funes H, Cervantes A, Freyer G, Papamichael D, Le Bail N, Louvet C, Hendler D, de Braud F, Wilson C, Morvan F, Bonetti A: Leucovorin and fluorouracil with or without oxaliplatin as first-line treatment in advanced colorectal cancer. J Clin Oncol 2000; 18(16):2938-47.

5 Cunningham D, Humblet Y, Siena S, Khayat D Bleiberg H, Santoro A, Bets D, Mueser M, Harstrick A, Verslype C, Chau I, Van Cutsem E: Cetuximab monotherapy and cetuximab plus irinotecan in irinotecan-refractory metastatic colorectal cancer. N Engl J Med 2004;351(4):337-45.
6 Hurwitz H, Fehrenbacher L, Novotny W, Cartwright T, Hainsworth J, Heim W, Berlin J, Baron A, Griffing S, Holmgren E, Ferrara N, Fyfe G, Rogers B, Ross R, Kabbinavar F: Bevacizumab plus irinotecan, fluorouracil, and leucovorin for metastatic colorectal cancer. N Engl J Med 2004; 350(23):2335-42.

7 Grothey A, Sargent D, Goldberg RM, Schmoll HJ: Survival of patients with advanced colorectal cancer improves with the availability of fluorouracilleucovorin, irinotecan, and oxaliplatin in the course of treatment. J Clin Oncol 2004;22(7) 1209-14.

8 Tournigand C, Andre T, Achille E, Lledo G, Flesh M, Mery-Mignard D, Quinaux E, Couteau C, Buyse M, Ganem G, Landi B, Colin P, Louvet C, de Gramont A: FOLFIRI followed by FOLFOX6 or the reverse sequence in advanced colorectal cancer: a randomized GERCOR study. J Clin Oncol 2004;22(2):229-37.

9 Raymond E, Boige V, Faivre S, Sanderink GJ, Rixe O, Vernillet L, Jacques C, Gatineau M, Ducreux M, Armand JP: Dosage adjustment and pharmacokinetic profile of irinotecan in cancer patients with hepatic dysfunction. J Clin Oncol 2002;20(21): 4303-12.

10 Venook AP, Enders Klein C, Fleming G, Hollis D, Leichman CG, Hohl R, Byrd J, Budman D, Villalona M, Marshall J, Rosner GL, Ramirez J, Kastrissios H, Ratain MJ: A phase I and pharmacokinetic study of irinotecan in patients with hepatic or renal dysfunction or with prior pelvic radiation: CALGB 9863. Ann Oncol 2003;14(12): 1783-90.
11 Lenz HJ, Van Cutsem E, Khambata-Ford S, Mayer RJ, Gold P, Stella P, Mirtsching B, Cohn AL, Pippas AW, Azarnia N, Tsuchihashi Z, Mauro DJ, Rowinsky EK: Multicenter phase II and translational study of cetuximab in metastatic colorectal carcinoma refractory to irinotecan, oxaliplatin, and fluoropyrimidines. J Clin Oncol 2006;24(30) 4914-21.

12 Giantonio BJ, Catalano PJ, Meropol NJ, O'Dwyer PJ, Mitchell EP, Alberts SR, Schwartz MA, Benson AB 3rd: Bevacizumab in combination with oxaliplatin, fluorouracil, and leucovorin (FOLFOX4) for previously treated metastatic colorectal cancer: results from the Eastern Cooperative Oncology Group Study E3200. J Clin Oncol 2007;25(12): 1539-44.

13 Nolting A, Fox FE, Kovar A: Clinical drug development of cetuximab, a monoclonal antibody; in Meibohm B (ed): Pharmacokinetics and Pharmacodynamics of Biotech Drugs: Principles and Case Studies in Drug Development. Weinheim, Wiley$\mathrm{VCH}, 2006$.

14 Saltz L, Lenz H-J, Hochster H, Wadler S, Hoff P, Kemeny N, Hollywood E, Gonen M, Wetherbee S, Chen H: Randomized phase II trial of cetuximab/ bevacizumab/irinotecan (CBI) versus cetuximab/ bevacizumab (CB) in irinotecan-refractory colorectal cancer. ASCO Annu Meet Proc 2005;3508.

15 Saltz L, Kies MS, Abbruzzese JL, Azarnia N, Needle MN: The presence and intensity of the cetuximab-induced acne-like rash predicts increased survival in studies across multiple malignancies. ASCO Annu Meet Proc 2003;817. 